\title{
Incidence and Outcome of Surfactant Therapy in Premature Neonates in ICU of KAMC
}

\author{
Farhan A. Enezi ${ }^{1}$, Sreekanth Mohan ${ }^{1}$, Khalid Fuad Alghamdi ${ }^{1}$, \\ Abdulrhman Mubarak D. Alenzi ${ }^{1}$, Khalid Ahmed Alrashidi ${ }^{1}$, Abdullah Abdulaziz A. \\ Almajed ${ }^{1}$, Faisal Eid Alqithami ${ }^{1}$, Winnie Philip ${ }^{2}$ and Shoeb Qureshi ${ }^{2 *}$ \\ ${ }^{1}$ Respiratory Therapy Department, College of Applied Medical Sciences, King Saud Bin \\ Abdulaziz University, Riyadh, Saudi Arabia \\ ${ }^{2}$ Research Department, College of Applied Medical Sciences, King Saud Bin Abdulaziz \\ University, Riyadh, Saudi Arabia \\ *Corresponding author
}

\begin{tabular}{|c|}
\hline Keywords \\
\hline $\begin{array}{l}\text { Premature neonates, } \\
\text { Surfactant } \\
\text { deficiency, } \\
\text { Respiratory distress, } \\
\text { Survanta, Infasurf }\end{array}$ \\
\hline Article Info \\
\hline $\begin{array}{l}\text { Accepted: } \\
12 \text { March } 2018 \\
\text { Available Online: } \\
10 \text { April } 2018\end{array}$ \\
\hline
\end{tabular}

\section{A B S T R A C T}

Lung surfactant plays a key role in adequate pulmonary function throughout life. Since Surfactant replacement therapy has been introduced in 1980s, it has proven its effect in premature neonates with surfactant deficiency. Since surfactant therapy is important in various respiratory conditions in premature neonates, this proposed study reviews the incidence, outcome $\&$ their clinical issues in surfactant replacement therapy. The objective of the study is to assess the outcome of surfactant therapy in premature neonates, to find out the length of hospital stay. The secondary objective is to find the mortality rate, the effect of early administration of surfactant in premature surfactant deficient neonates. The study was conducted in neonatal intensive care units of King AbdulAziz Medical City (KAMC), Riyadh and study subjects include premature neonates undergone surfactant therapy in ICU. A sample size of 110 neonates from a population of 150 premature neonates in neonatal ICU of KAMC was selected. Out of the total 109 subjects, 69 were males and 40 were females. The mean gestational age was 30 weeks. The majority $(n=83,76.15 \%)$ had Respiratory Distress Syndrome (RDS). Subjects were treated with surfactant replacement therapy with either survanta $(50.5 \%)$ or Infasurf $(49.5 \%)$. The mean APGAR scoring at 1 and 6 minutes was statistically significant $(\mathrm{P}=0.001)$. Vital signs such as temperature (sd$0.58, \mathrm{P}=0.017)$, respiratory rate $(\mathrm{sd}-15.86, \mathrm{p}=0.001)$, and heart rate $(\mathrm{sd}-17.84, \mathrm{p}=$ 0.046) compared with improved and expired subjects and were statistically significant. Arterial blood gas in pre and post surfactant therapy was statistically significant with $\mathrm{pH}(\mathrm{p}=0.001), \operatorname{Pco} 2(\mathrm{p}=0.001)$, and base excess $(\mathrm{p}=0.001)$. The administration of surfactant therapy can improve the total outcome of premature infants with respiratory distress. This study favors early use and benefits of surfactant therapy which has proven by many other relevant articles published earlier. This study shows good results after administration of surfactants like survanta and infasurf. 


\section{Introduction}

Lung surfactant plays a key role in adequate pulmonary function throughout life. The alveoli are covered with a thin film of lung surfactant that reduces the surface tension in the lung, which results in decreased work of breathing thus to confirm uniform lung inflation (Zasadzinski et al., 2001) Since Surfactant replacement therapy has been introduced in 1980s, it has proven its effect in premature infants with surfactant deficiency (Mazela et al., 2006). Several Randomized control trials (RCT) has proven the effectiveness of Surfactant replacement therapy in lung diseases such as Meconium aspiration syndrome (MAS) neonatal pneumonia, Acute respiratory distress syndrome (ARDS) and Acute lung injury (ALI) (Robertson and Halliday, 1998).

In 1959, Avery and Mead reported on lack of surfactant in the lungs of premature infants with respiratory distress syndrome (RDS) (Avery and Mead, 1959; Robillard et al., 1964). This led to clinical attempts of artificial surfactant in infants with (RDS). Surfactants have been studied in several well-designed randomized controlled experiments, which make possible this comprehensive analysis of indications, risks and advantages (Chu et al., 1967). Surfactant replacement was established as an effective and safe therapy for immaturity-related surfactant deficiency by early 1990s (Engle, 2008). Mechanical ventilation is frequently needed for the management of respiratory distress syndrome even though the lung injury induced by the ventilator can lead to ineffective production of endogenous surfactant thus reflects the prognostication of surfactant replacement therapy (Bjorklund et al., 1997). Direct tracheal instillation of surfactant has shown a reduce in death rate and morbidity rate in infants with RDS (Berry et al., 1994). This clinical report refreshes a 2008 report from the
American Academy of Pediatrics (Soll, 2000). As in a report, number of clinically important topics is reviewed surrounding use of surfactant, including prophylactic versus rescue replacement, administration techniques and preparations, the synergistic effects of surfactant and antenatal steroids, and surfactant therapy for respiratory disorders other than RDS (Bahadue and Soll, 2012).

Even though there is a paucity of data, it is likely to have worsening of pulmonary hypoplasia in infants who received surfactant replacement therapy (Van Meurs, 2004). Additionally, the use of continuous positive airway pressure on RDS, surfactant replacement and the efficacy of the INSURE approach (intubation, surfactant administration, and extubation to CPAP) has proven its effect in premature infants with RDS (Suresh and Soll, 2005). Deficiency of surfactant is the most common cause of death in neonates (Liu et al., 2015). Out of 6.3 million neonates who died in 2013, about 1 million $(15.4 \%)$ died due to deficiency of surfactant (Fehlmann et al., 2010).

The major contributing factor for the efficacy of surfactant therapy is its lipid and protein content and the technique of its usage.it is being said that whatever the technique, to have a maximum result surfactant should provide uniform distribution in the respiratory tract. (Ueda et al., 1994) The major morbidities that result in deaths in preterm neonates include RDS, necrotizing enterocolitis and intraventricular haemorrhage (Fehlmann et al., 2010).

A study conducted in neonates to find out the response of multiple surfactant dosage revealed an improvement in lung function (Lang et al., 1988). RDS, in addition to being a direct reason of mortality, also contributes indirectly by increasing the risk of intraventricular hemorrhage, broncho 
pulmonary dysplasia and nosocomial infections such as ventilator-associated pneumonia (Kumar and Bhat, 1996). A Comparative study to find out clinical responses to natural and synthetic surfactants had concluded that there are no statistical clinical differences between both surfactants in mortality (Pfister et al., 2007).

Since surfactant therapy plays a vital role in various respiratory conditions in premature infants, this proposed study reviews the incidence, outcome \& their clinical issues in surfactant replacement therapy.

The aim of this study to determine the Incidence, outcome and related risks of premature neonates admitted in the Intensive Care Unit (ICU) of King Abdulaziz Medical city (KAMC).

\section{Specific objectives}

To assess the primary outcome of the surfactant therapy in premature neonates/infants.

To find out the length of hospital stay.

To know which gender had under gone more surfactant replacement therapy.

\section{Secondary objectives}

To rule out the major complications if present.

To find out the mortality rate among surfactant deficient premature neonates/infants.

To identify the effect of early administration of surfactant therapy in premature babies with surfactant deficiency.

\section{Materials and Methods}

\section{Study area/setting}

The study will be conducted in neonatal intensive care units of King AbdulAziz Medical City (KAMC), Riyadh, Saudi Arabia.

The intensive care units are covered by Intensivists, Respiratory Therapists and Critical care nurses 24 hours per day, 7 days a week.

\section{Study subjects}

All premature neonates/infant who had undergone surfactant therapy in neonatal ICU will be taken for the study.

\section{Inclusion criteria}

Infants who had surfactant therapy as advised by neonatologist.

Gestational age less than 35 weeks.

Both male and female age groups.

Infants who born in KAMC.

\section{Exclusion criteria}

Infants born in hospitals other than KAMC.

Hemodynamically unstable subjects.

Incomplete data recording.

Lack of arterial blood gas analysis (ABG) before surfactant administration..

Subjects with severe congenital abnormalities. 


\section{Study design}

A Quantitative retrospective study.

\section{Sample size}

From a total population of 150 premature infants /neonates in neonatal ICU of KAMC with a margin of error of $5 \%$ and a confidence level of $95 \%$, the sample size observed as per check market online sample size calculator is 109 , fixed as 110 premature infants/neonates.

\section{Sampling technique}

The subjects for the study will be selected by using simple random sampling technique.

Data collection methods, instruments used, measurements

Data like diagnosis, date and time of surfactant therapy, frequency of surfactant therapy administration, types of surfactant used, APGAR score during 1 minute \& 6 minutes, whether the patient is on mechanical ventilation, non-invasive ventilation, on oxygen etc. will be collected from the health charts of the selected subjects Mechanical ventilator parameters, $\mathrm{ABG}$, vital signs, will be collected from Respiratory Therapy Charts, Critical care flow sheets and electronic medical records. The factors like total number of surfactant therapy cases, outcome and related risks of premature neonates in ICU, length of ICU stay, readmission to ICU will also be collected and recorded. Data collection sheet is attached as Appendix I.

\section{Data management and analysis plan}

The data will be entered in Microsoft Excel sheets and the statistical analysis of the variables will be carried out by using SPSS software version 22. A backup soft copy version as well as a hard copy will be dated, saved and secured after each data entry update. A designated study binder and a dedicated USB flash memory will be kept with principal investigator.

\section{Ethical considerations: Informed Consent}

Instructions: If needed, please attach Informed Consent and/or extra documents. Translated forms are provided when needed

The study will be conducted only after getting IRB approval.

The personal information of the patient will be kept strictly confidential.

Any document which can disclose the identity of the subject will not be collected nor used in any part of the study or research document.

\section{Results and Discussion}

The selected subjects who met the inclusion criteria in this study was $109(\mathrm{n}=109)$. They were below 38 weeks of gestational age.

The maximum gestational age was 37 weeks with a mean gestational age of 30 weeks (Table 1). In this mixed population, the male subjects were $69(\mathrm{n}=69)$ which forms $(63.3 \%)$ and females were $40(n=40)$ which comprise (36.7\%) (Figure 1).

There were various reasons for surfactant replacement therapy. The majority of the subjects had Respiratory distress syndrome (RDS) ( $\mathrm{n}=83$ ) which form $(76.15 \%)$. The second majority subjects $(\mathrm{n}=40)$ had severe prematurity which was $(36.7 \%)$. The other subjects with conditions like low birth weight, respiratory failure, transient tachypnea, atrial septal defect, ventricular septal defect who received surfactant replacement therapy were negligible ( $\mathrm{n}=1),(0.92 \%)$ (Figure 2$)$. 
Table.1 Gestational age in weeks

\begin{tabular}{|l|}
\hline Mean \\
\hline Std. Deviation \\
\hline Minimum \\
\hline Maximum \\
\hline
\end{tabular}

\begin{tabular}{|c|}
\hline 30.29 \\
\hline 4.193 \\
\hline 2 \\
\hline 37 \\
\hline
\end{tabular}

Table.2 Comparison of APGAR score at 1 minute and 6 minute

\begin{tabular}{|l|l|r|r|r|r|}
\hline $\begin{array}{l}\text { APGAR } \\
\text { score }\end{array}$ & n & Mean & SD & T value & P value \\
\hline $\mathbf{1}$ min & 109 & 5.38 & 2.13 & & \\
\hline $\mathbf{6}$ min & 109 & 7.51 & 1.31 & -14.700 & $0.001 *$ \\
\hline
\end{tabular}

Table.3 Descriptive statistics on ICU duration

\begin{tabular}{|l|r|r|r|r|r|}
\hline & N & Minimum & Maximum & Mean & $\begin{array}{c}\text { Std. } \\
\text { Deviation }\end{array}$ \\
\hline $\begin{array}{l}\text { ICU duration } \\
\text { (in days) }\end{array}$ & 109 & 1 & 152 & 43.58 & 34.59 \\
\hline
\end{tabular}

Table.4 Comparing the outcome and other variables

\begin{tabular}{|l|c|c|c|c|c|c|}
\hline Variable & Outcome & $\mathrm{n}$ & Mean & SD & $\begin{array}{c}\text { Value of } \\
\text { Statistic }\end{array}$ & $\begin{array}{c}\text { P } \\
\text { value }\end{array}$ \\
\hline $\begin{array}{c}\text { Length of } \\
\text { stay in ICU }\end{array}$ & Death & 8 & 55.00 & 45.92 & $\mathrm{~T}=0.970$ & 0.334 \\
\hline $\begin{array}{c}\text { Gestational } \\
\text { age (in } \\
\text { weeks) }\end{array}$ & Death & 101 & 42.67 & 33.67 & & \\
\hline
\end{tabular}

Table.5 Comparison of vital signs among the subjects

\begin{tabular}{|c|c|c|c|c|c|c|}
\hline Variable & Outcome & $\mathrm{n}$ & Mean & SD & $\begin{array}{l}\text { Value of } \\
\text { Statistic }\end{array}$ & P value \\
\hline \multirow{2}{*}{$\begin{array}{l}\text { Temperature } \\
\text { (degree Celsius) }\end{array}$} & Death & 8 & 36.13 & 0.35 & \multirow{2}{*}{$\mathrm{T}=-2.835$} & \multirow{2}{*}{$0.017 *$} \\
\hline & Improved & 101 & 36.51 & 0.58 & & \\
\hline \multirow{2}{*}{$\begin{array}{l}\text { Respiratory rate } \\
(\mathrm{bpm})\end{array}$} & Death & 8 & 35.25 & 6.49 & \multirow[t]{2}{*}{$\mathrm{T}=-4.546$} & \multirow[t]{2}{*}{$0.001^{*}$} \\
\hline & Improved & 101 & 47.92 & 15.86 & & \\
\hline \multirow{2}{*}{$\begin{array}{l}\text { Heart rate } \\
(\mathrm{bpm})\end{array}$} & Death & 8 & 129.75 & 33.63 & \multirow[t]{2}{*}{$\mathrm{T}=-2.393$} & \multirow[t]{2}{*}{$0.046^{*}$} \\
\hline & Improved & 101 & 158.51 & 17.84 & & \\
\hline \multirow[t]{2}{*}{ SPO2 } & Death & 8 & 73.50 & 27.45 & \multirow[t]{2}{*}{$\mathrm{T}=-1.916$} & \multirow[t]{2}{*}{0.096} \\
\hline & Improved & 101 & 40.29 & 32.08 & & \\
\hline
\end{tabular}


Table.6 Comparison of ABG values $(n=100)$

\begin{tabular}{|l|c|c|c|c|c|}
\hline $\begin{array}{l}\text { ABG } \\
\text { parameters }\end{array}$ & $\begin{array}{c}\text { Pre and post } \\
\text { surfactant therapy }\end{array}$ & Mean & SD & T value & P value \\
\hline pH & pre & 7.28 & 0.09 & -6.638 & $0.001 *$ \\
\hline \hline PaC02 & post & 7.34 & .08 & & \\
& pre & 51.02 & 13.81 & 5.811 & $0.001 *$ \\
\hline PaO2 & post & 43.31 & 10.13 & & \\
\hline pre & 55.20 & 19.50 & 0.057 & 0.955 \\
\hline post & 54.94 & 43.79 & & \\
\hline BE & pre & 22.35 & 3.49 & -0.097 & 0.923 \\
& post & 22.39 & 3.85 & & \\
\hline
\end{tabular}

Fig.1 Pie diagram showing the gender distribution of study subjects

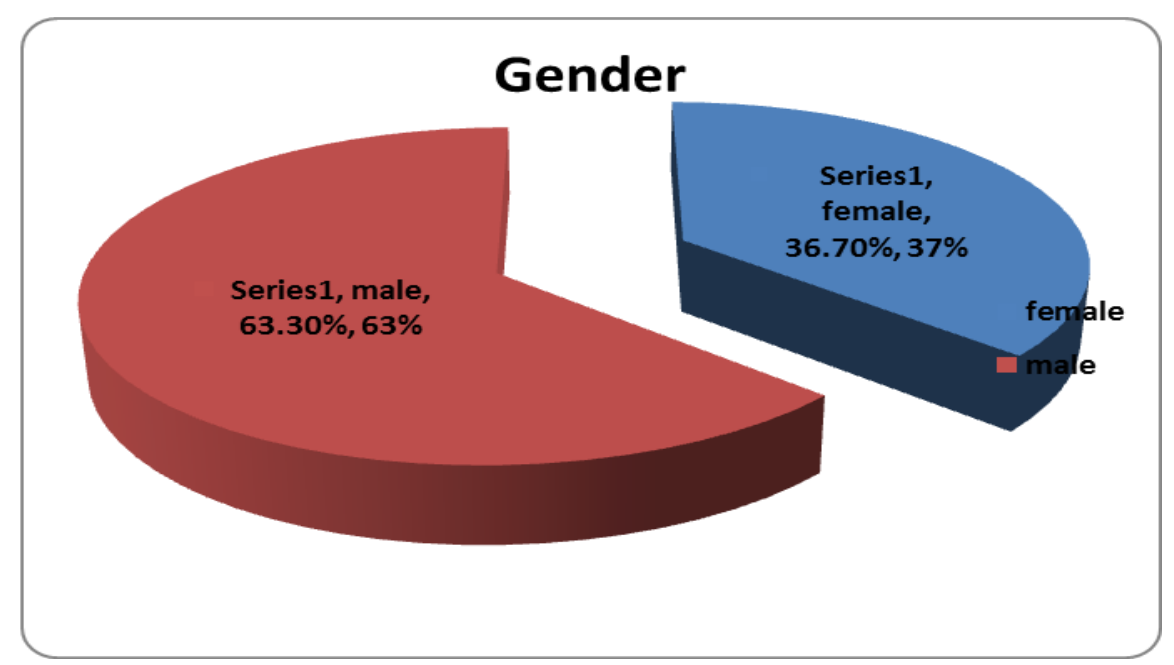

Fig.2 Bar diagram showing the diagnosis of study subjects

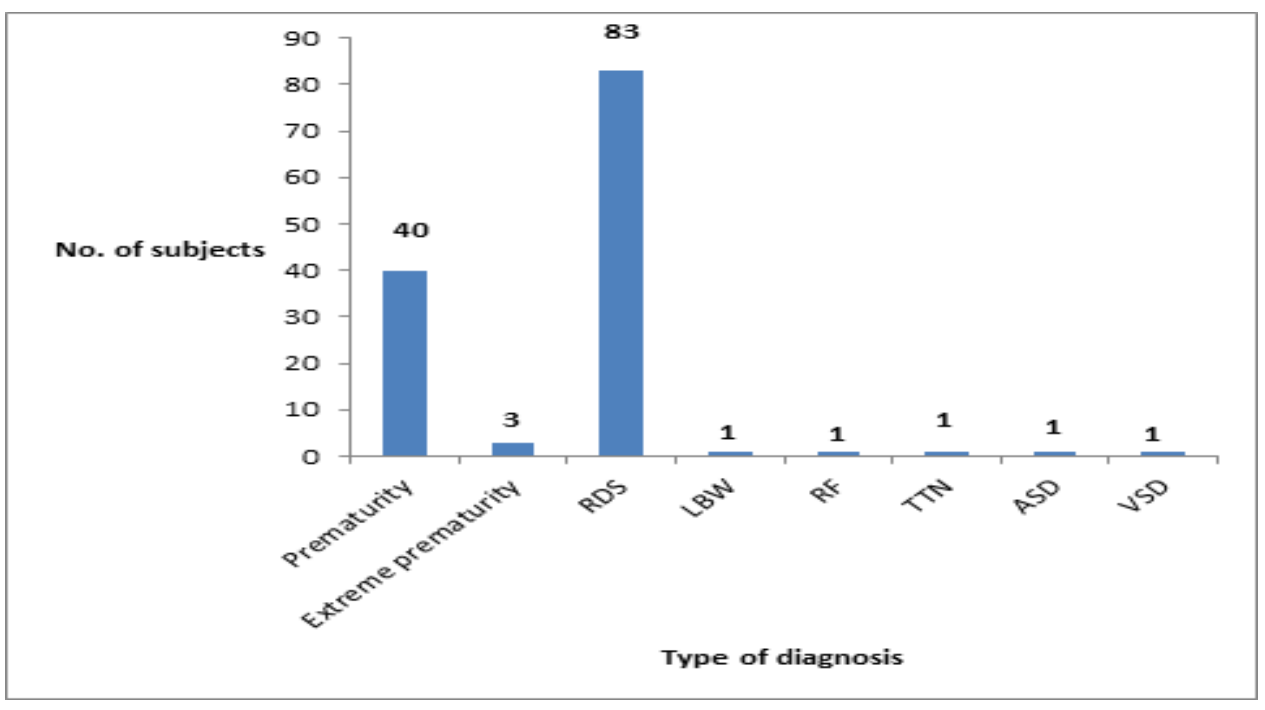


Fig.3 Pie diagram showing the type of surfactant used for the subjects

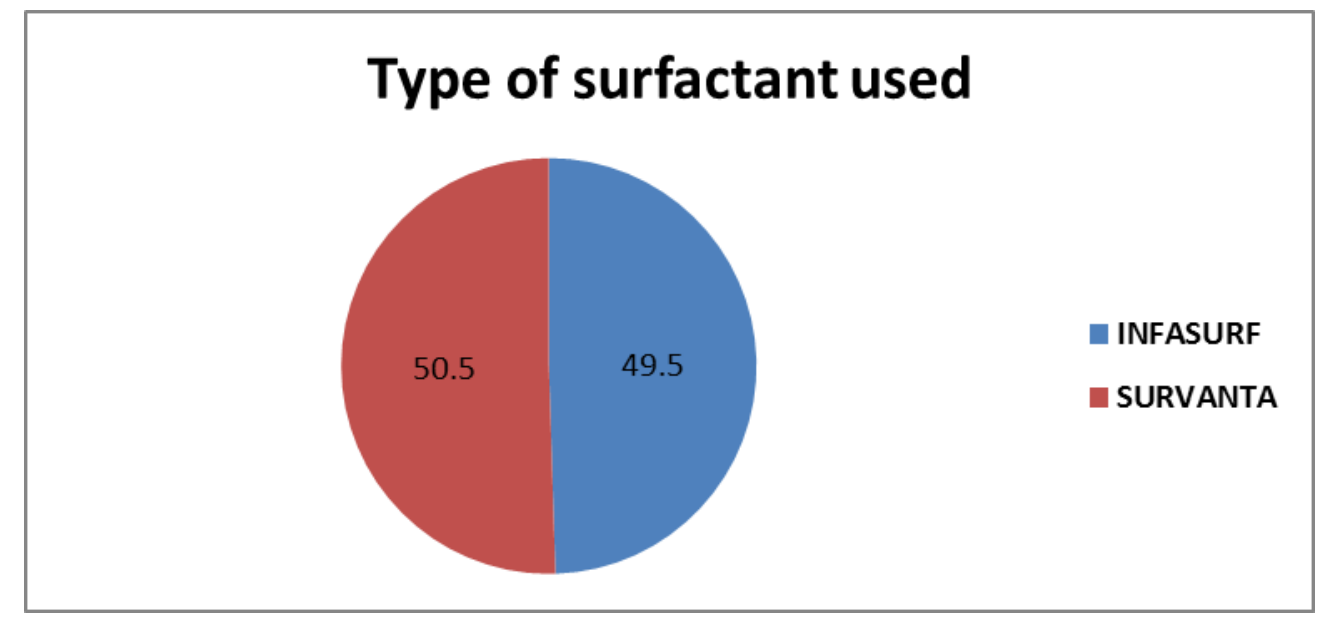

Fig.4 Pie diagram showing the outcome of surfactant replacement therapy

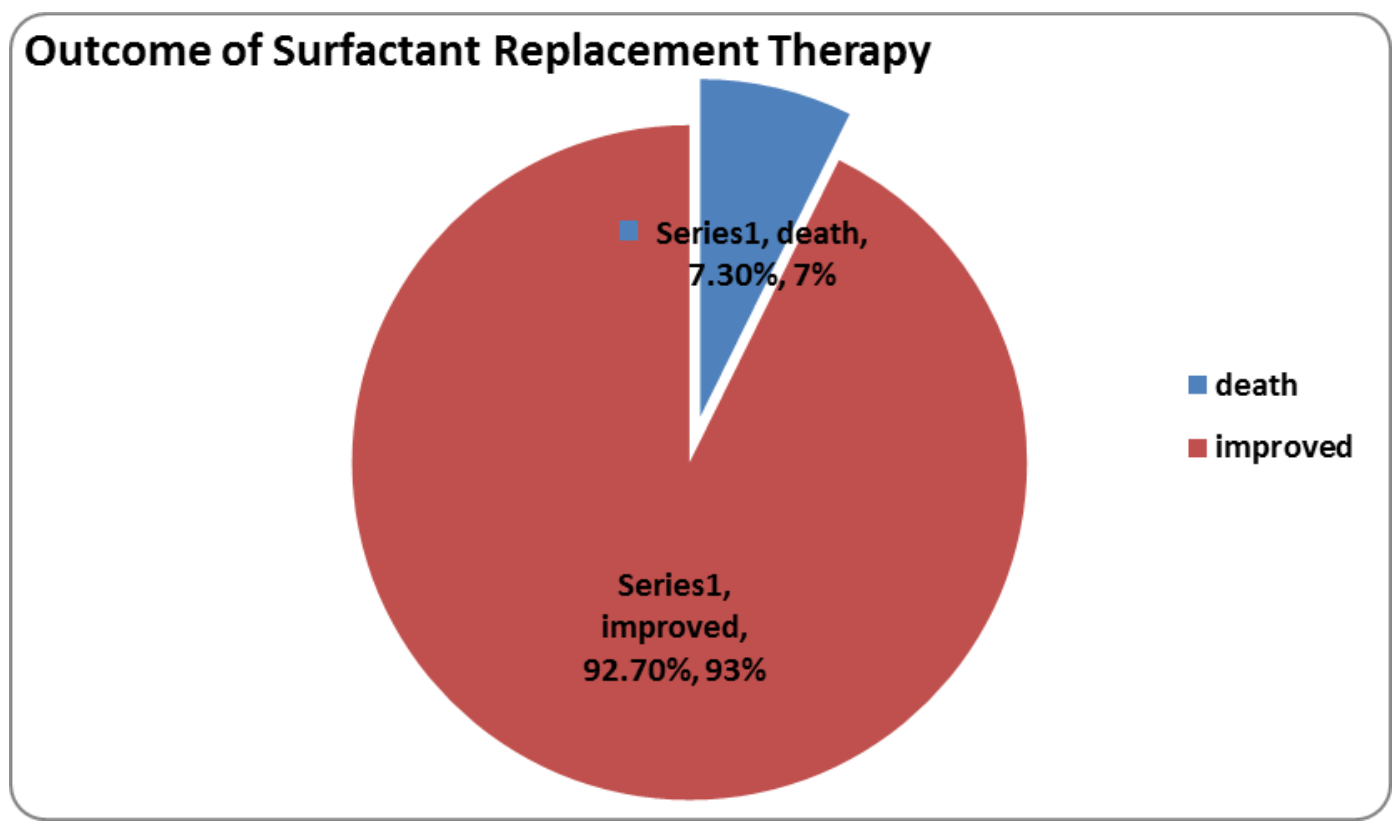

The subjects were treated with infasurf a natural surfactant obtained from calf lungs and survanta a different variety of bovine pulmonary surfactant containing bovine lung extract.

The use of surfactant survanta was a little higher $(50.5 \%)$ than the use of Infasurf which was $(49.5 \%)$ only (Figure 3 ). The main indication for the use of surfactant replacement therapy (SRT) was surfactant deficiency since the neonates were born premature. The frequency of surfactant dosage was single dose $(n=72)$ which is $(66.1 \%)$, two doses $(n=27)$ which is $(24.8 \%)$, three doses $(n=9)$ which is $(8.3 \%)$ and four doses $(n=1)$ which is $(0.9 \%)$. The mean ICU duration in invasive mechanical ventilation was (44.72) whereas the mean duration in noninvasive mechanical ventilation was (40.29) with a $\mathrm{p}$ value (P: 0.562$)$ which is not statistically significant. 
APGAR score was monitored in these subjects. It was recorded in 1 and 6 minutes after birth. The mean APGAR scoring in 1 minute was (5.38) with standard deviation (SD: 2.13) and the mean APGAR at 6 minutes was (7.51) with standard deviation (1.31). The $P$ value in APGAR score during 1 and 6 minutes is $(\mathrm{p}=0.001)$ which shows significance (Table 2). 8 of the total subjects $(n=8)$ which comes only $(7.3 \%)$ got expired whereas the majority of the subjects $(n=101)$ which comes approximately (92.7\%) improved (Figure 4). 53 subjects (52.5\%) were shifted to other minor hospitals, 46 subjects $(45.5 \%)$ were discharged to home and $2(2 \%)$ were shifted to intensive care nursery in the same hospital. The maximum duration in the Intensive Care Unit (ICU) was 152 days and the minimum duration was 1 day with a mean duration of (43.58) days and a standard deviation of (34.59) (Table 3).

A comparison was done between subject's outcome and some of the variables like length of ICU stay, gestational age, type of ventilation (Table 4) and found that those who had a mean gestational age of (30.76) got improved and those who were with a mean gestational age of 24.38 expired with a standard deviation (SD: 3.884) and (3.543) respectively with a statistical significance $(\mathrm{P}$ 0.001). Other variables did not have significance. The outcome was also compared with vital signs. In this comparison it revealed that those subjects $(n=101)$ with mean body temperature of (36.51 degree Celsius) and a standard deviation of (SD: 0.58) improved whereas those subjects $(n=8)$ with a mean temperature of (36.13) and a standard deviation of (0.35) expired and showed statistical significance (P: 0.017). Respiratory rate of improved and expired with mean rate of 35.25 and 47.92 respectively and a standard deviation of 15.86 and 6.49 respectively were significant with a $\mathrm{p}$ value $(\mathrm{P}=0.001)$. Heart rate among the improved and expired subjects was also compared and found a mean heart rate of $158.51 \mathrm{~b} / \mathrm{min}$ in improved and a mean heart rate of $129.75 \mathrm{~b} / \mathrm{min}$ in expired subjects with a standard deviation (SD: 33.63 and 17.84 respectively) and was statistically significant with $\mathrm{p}$ value (P:0.046) (Table 5). An Arterial Blood Gas (ABG) analysis was done pre and post surfactant administration and showed a statistical significance in $\mathrm{pH}$ with a $\mathrm{P}$ value (p: 0.001) and an improvement in $\mathrm{PaCO}_{2}$ in post surfactant administration with a $\mathrm{p}$ value (P: 0.001) which is also clinically significant. It was also found that there is an improvement in Base Excess (BE) by -3.40 post from -5.23 pre which is also considered as statistically significant with $\mathrm{p}$ value (P: 0.001) (Table 6).

This study investigated the primary outcome of the surfactant therapy in premature neonates, who had under gone more surfactant replacement therapy during 2016, to find out the mortality rate among surfactant deficient premature neonates and also to identify the effect of early administration of surfactant therapy in premature neonates. The results in this study have proven that the mortality was very low among premature subjects and majority of them were improved and shifted from ICU which support the study conducted by Suresh and Soll (2005) during 23 and 34 weeks gestational aged premature neonates but it was not agreed by the findings of Sankar et al., (2016) who found no difference in the risk of mortality in one of their randomized control trial. This study divulged that early administration of surfactant plays an important role in the prognosis of premature neonates with surfactant replacement therapy. This correlates with the findings of Bahadue and Soll (2012) a meta-analysis of initial hours versus late surfactant therapy concluded that the risks of mortality were significantly decreased in premature age group. This was contrary to the study conducted by Kendig et al., (1998) which showed no significant difference clinically in result between 
instantaneous administration of prophylactic surfactant and administration at $10 \mathrm{~min}$ after birth after a brief period of stabilization. Out of the total number of subjects (109), 101 improved while 8 died. The maximum duration of Intensive Care Unit was 152 days. The majority of the subjects who had undergone surfactant replacement therapy were males $(69,63.3 \%)$ and females (40, $36.7 \%)$. The type of surfactant used was survanta in two doses $(50.5 \%$ and $49.5 \%)$ were administered with infasurf. (Lim et al., 1998) identified a sudden and extremely major progress in $\mathrm{FiO} 2$, mean airway pressure, arterial/alveolar oxygen tension ratio and ventilatory index in neonates with respiratory distress syndrome (RDS) requiring mechanical ventilation with $\mathrm{FiO} 2$ of $>$ or $=$ $40 \%$ who were treated with Survanta. A similar study conducted by (Pramanik et al., 1993) stated that pulmonary surfactant agents which are artificial or non-human source given as preventive or lifesaving treatment efficiently decrease death rate among RDS patients. Eighty one of the subjects were on invasive mechanical ventilator with a mean duration of 40 days. A study done by Svenningsen et al., (1987) found that a short duration of intermittent positive-pressure ventilation during the treatment with surfactant can improve the effect of surfactant administration and thus overall prognosis of the patient. There were no major complications present during the ICU stay. The mortality rates of the subjects were very low (7.3\%). In this study, those subjects with a mean gestational age of 24 weeks showed maximum improvement than those subjects with mean gestational age of 30 weeks. There was an improvement in temperature, respiratory rate and heart rate between pre and post surfactant administration which was statistically significant. There were significant changes in $A B G$ values pre and post surfactant therapy which also had statistical significance.
There is no doubt that the administration of surfactant therapy can improve the total outcome of premature infants with respiratory distress. This study favors early use and benefits of surfactant therapy which has proven by many other relevant articles published earlier. This study shows good results after administration of artificial surfactants like survanta and infasurf. Limitation of this study includes difficulty in accessing the patients, lack of availability of patients who fits to the study's inclusion criteria. Since this study did not mention the birth weight of the preterm and their outcome, further studies may be needed to see the outcomes of premature infants according to their gestational age and birth weight.

\section{Acknowledgement}

We express our gratitude to International Review Board, King Abdullah International Medical Research Center for necessary approval of research proposal and King Saud Bin Abdul-aziz University for Health Sciences for providing facilities to undertake the research. We would also like to thank everyone who gave us an access to collect our data from Best Care System of KAMC.

\section{References}

Avery ME, and Mead J. Surface properties in relation to atelectasis and hyaline membrane disease. Am J Dis Child 1959; 97:517-23.

Bahadue FL, and Soll R, Early versus delayed selective surfactant treatment for neonatal respiratory distress syndrome. Cochrane Database Syst Rev. 2012 Nov 14. (11): CD001456.

Bahadue FL, Soll R. Early versus delayed selective surfactant treatment for neonatal respiratory distress syndrome. Cochrane Database Syst Rev. 2012; 11(11):CD001456. 
Berry DD, Pramanik AK, Philips JB 3rd., Buchter DS, Kanarek KS, Easa D, et al., Comparison of the effect of three doses of a synthetic surfactant on the alveolararterial oxygen gradient in infants weighing $\geq 1250$ grams with respiratory distress syndrome. American Exosurf Neonatal Study Group II. J Pediatr 1994; 124(2):294-301.

Bjorklund LJ, Ingimarsson J, Curstedt T, John $\mathrm{J}$, Robertson B, Werner $\mathrm{O}$, et al., Manual ventilation with a few large breaths at birth compromises the therapeutic effect of subsequent surfactant replacement in immature lambs. Pediatr Res 1997; 42(3):348355.

Chu J, Clements JA, Cotton EK. Neonatal pulmonary ischemia: Clinical and physiologic studies. Pediatrics 1967; 40(Suppl):709-82

Engle WA, American Academy of Pediatrics Committee on Fetus and Newborn. Surfactant-replacement therapy for respiratory distress in the preterm and term neonate. Pediatrics. 2008; 121(2):419-432.

Fehlmann E, Tapia JL, Fernandez R, Bancalari A, Fabres J, D'Apremont I et al., (Impact of respiratory distress syndrome in very low birth weight infants: a multicenter South-American study). Arch Argent Pediatr 2010; 108(5): 393-400.

Fehlmann E, Tapia JL, Fernandez R, Bancalari A, Fabres J, D'Apremont I et al., (Impact of respiratory distress syndrome in very low birth weight infants: a multicenter South-American study). Arch Argent Pediatr 2010; 108(5): 393-400.

Kendig JW, Ryan RM, Sinkin RA, Maniscalco WM, Notter RH, Guillet R, et al., Comparison of two strategies for surfactant prophylaxis in very premature infants: a multicenter randomized trial. Pediatrics. 1998; 101(6):1006-12.

Kumar A, and Bhat BV. Epidemiology of respiratory distress of newborns. Indian J Pediatr 1996; 63(1): 93-98.

Lang MJ, Rhodes PG, Reddy NS, Kurth G, Merritt A. et al., Limitation of the effective use of human surfactant (HS) in established RDS. Pediatr Res. 1988; 23:513

Lim WL, Lim CT, Chye JK. The effectiveness of surfactant replacement therapy for preterm infants with respiratory distress syndrome. Med J Malaysia 1998; 53(4): 376-384

Liu L, Oza S, Hogan D, Perin J, Rudan I, Lawn JE et al., Global, regional, and national causes of child mortality in 2000-13, with projections to inform post-2015 priorities: an updated systematic analysis. Lancet, 2015; 385(9966): 430-440

Mazela J, Merritt TA, Gadzinowski J, Sinha S. Evolution of pulmonary surfactants for the treatment of neonatal respiratory distress syndrome and paediatric lung diseases. Acta Paediatr. 2006; 95(9):1036-1048.

Pfister RH, Soll RF, Wiswell T. Protein containing synthetic surfactant versus animal derived surfactant extract for the prevention and treatment of respiratory distress syndrome. Cochrane Database Syst Rev. 2007.(3): CD006069.

Pramanik AK, Holtzman RB, Merritt TA. Surfactant replacement therapy for pulmonary disease. Pediatr Clin North Am. 1993; 40:913-936.

Robertson B, and Halliday HL. Principles of surfactant replacement. Biochim. Biophys. Acta. 1998; 1408(2):346-361.

Robillard E, Alarie Y, Dagenais-Perusse P, Baril E, Guilbeault A. Microaerosol administration of synthetic dipalmitoyl lecithin in the respiratory distress syndrome: A preliminary report. 
Canadian Medical Association Journal 1964; 90:55-7.

Sankar, MJ, Gupta N, Jain K, Agarwal R, and Paul VK. Efficacy and safety of surfactant replacement therapy for preterm neonates with respiratory distress syndrome in low- and middleincome countries: a systematic review. J Perinatol. 2016; 36 Suppl 1: S36-48.

Soll RF, Synthetic surfactant for respiratory distress syndrome in preterm infants. Cochrane Database Syst Rev. 2000; (2):CD001079.

Suresh GK, and Soll RF, Overview of surfactant replacement trials. J Perinatol. 2005; 25:S40-S44.

Suresh GK, Soll RF. Overview of surfactant replacement trials. J Perinatol. 2005; 25(suppl 2):S40-S44.

Svenningsen N, Robertson B, Andreason $\mathrm{B}$, Berggren $\mathrm{P}$, Jonson $\mathrm{B}$, Lindroth $\mathrm{M}$.
Endotracheal administration of surfactant in very low birth weight infants with respiratory distress syndrome. Crit Care Med 1987; 15(10); 918-22.

Ueda T, Ikegami M, Rider ED, Jobe AH. Distribution of surfactant and ventilation in surfactant-treated preterm lambs. J Appl Physiol. 1994;76:45-55

Van Meurs K. Is surfactant therapy beneficial in the treatment of the term newborn infant with congenital diaphragmatic hernia? J Pediatr 2004;145(3):312-316.

Zasadzinski J, Ding J, Warriner H, Bringezu F, Waring AJ. The physics and physiology of lung surfactants. Curr. Opin. Colloid Interface Sci. 2001; 6(5):506-513.

\section{How to cite this article:}

Farhan A. Enezi, Sreekanth Mohan, Khalid Fuad Alghamdi, Abdulrhman Mubarak D. Alenzi, Khalid Ahmed Alrashidi, Abdullah Abdulaziz A. Almajed, Faisal Eid Alqithami, Winnie Philip and Shoeb Qureshi. 2018. Incidence and Outcome of Surfactant Therapy in Premature Neonates in ICU of KAMC. Int.J.Curr.Microbiol.App.Sci. 7(04): 1548-1558.

doi: https://doi.org/10.20546/ijcmas.2018.704.174 